\title{
Otitis Media
}

National Cancer Institute

\section{Source}

National Cancer Institute. Otitis Media. NCI Thesaurus. Code C34885.

Inflammation of the anatomical structures of the middle ear, which is most often caused by an infectious process. Symptoms include erythema and edema of the tympanic membrane, pain, and possibly fever. 